\title{
Improving environmental assessment: methodological considerations and practical solutions
}

\author{
F. Bal ${ }^{1} \&$ J. M. Vleugel ${ }^{2}$ \\ ${ }^{1}$ RISSK, Haarlem, The Netherlands \\ ${ }^{2}$ Faculty of Civil Engineering and Geosciences, TU Delft, \\ The Netherlands
}

\begin{abstract}
In an environmental-economic analysis of a nature area, many explicit and implicit assumptions are used. Central actors, their preferences and behaviour concerning environmental goods are described. In tools, such as cost-benefit analysis, this framework is used to estimate the impact of environmental management (in particular investment decisions) by governments and other stakeholders. But, if these assumptions are not (completely) valid and if the datasets are incomplete and internally inconsistent, then the advice to policy makers may be incorrect. The impact of (environmental) policies may then become significantly different from what was expected. This does not necessarily mean, as some observers or lobbyists might argue, that such policies itself are useless. They can be influential if their design sufficiently reflects our knowledge of the system. As we will show, Bayesian synthetical inference is an interesting method to estimate a function which can be used to quantify the economic value of nature areas. In this way, possibly enhanced by some form of standardization, we may be able to increase the reliability of the outcomes of our analyses and broaden the application area of our tools and data. A practical example is used to strengthen our point.
\end{abstract}

Keywords: environmental assessment, meta-analysis, Bayesian, investments.

\section{Introduction}

In conventional in-depth nature area valuation studies the economic value of a site is estimated by using preferences of privies concerning the site 
characteristics. The result is a monetary variable, mostly the average willingnessto-pay (aWTP, for short) or consumer surplus value. The study finding(s) are largely context-specific. A researcher selects a set of moderator variables, i.e., the key determinants of the economic value of the study site, from a set of potential explanatory values within three groups (see Table 1).

Table 1: $\quad$ Moderator variables most frequently studied by scholars.

\begin{tabular}{|c|c|c|}
\hline \multirow[t]{6}{*}{$\begin{array}{l}\text { 1. Site } \\
\text { Specific } \\
\text { Variables }\end{array}$} & Land type & $\begin{array}{l}\text { Forest, wetland, desert, coastal area, } \\
\text { coral reef, etc. }\end{array}$ \\
\hline & Site size & \\
\hline & Ownership of the site & $\begin{array}{c}\text { Private, reservation agency, } \\
\text { governmental, etc. }\end{array}$ \\
\hline & $\begin{array}{c}\text { Conservation regime of the } \\
\text { site }\end{array}$ & $\begin{array}{l}\text { (inter)national park, biological station, } \\
\text { protected zone, fauna refuge, wildlife } \\
\text { refuge, etc. }\end{array}$ \\
\hline & Biodiversity & \\
\hline & $\begin{array}{l}\text { (Presence and level of) } \\
\text { economic activity }\end{array}$ & $\begin{array}{l}\text { Net revenue from products sold on the } \\
\text { market, net revenue from fulfilling } \\
\text { functions (e.g. water purification), etc. }\end{array}$ \\
\hline \multirow[t]{4}{*}{$\begin{array}{l}\text { 2. Study } \\
\text { Specific } \\
\text { Variables }\end{array}$} & Study type & $\begin{array}{c}\text { (in-depth) case study, (in-depth) } \\
\text { multiple case study, survey, choice } \\
\text { experimentation, Benefit Transfer / } \\
\text { Meta-analysis } \\
\end{array}$ \\
\hline & Valuation method & CBA, CVM, TC, HPM, etc. \\
\hline & Assessment method & $\begin{array}{l}\text { Game-theoretical methods, stochastic } \\
\text { methods, etc. }\end{array}$ \\
\hline & Sample information & $\begin{array}{l}\text { Sample size, probability distribution, } \\
\text { fixed priors, etc. }\end{array}$ \\
\hline \multirow[t]{5}{*}{$\begin{array}{l}\text { 3. Context } \\
\text { Specific } \\
\text { Variables } \\
\end{array}$} & Household characteristics & $\begin{array}{l}\text { Household size, household income, } \\
\text { etc. }\end{array}$ \\
\hline & Demographic charactristics & Age, sex, population density, etc. \\
\hline & $\begin{array}{l}\text { (Social-)economical } \\
\text { characteristics }\end{array}$ & Average income-level, PPP, etc. \\
\hline & $\begin{array}{l}\text { Period in time the study is } \\
\text { undertaken }\end{array}$ & \\
\hline & Location of the site & Region, country, etc. \\
\hline
\end{tabular}

The selection implies the use of a ceteris paribus clause. This makes such a study a partial investigation. In practice, a considerable variety in study approaches can be found, with a similar variety in the moderator variables studied. But, how robust are such endogenous estimates and how cost-efficient is such an approach, especially, because it is not unusual to observe major 
differences or even conflicting outcomes among earlier undertaken case studies for the same site? This makes a comparison of the study findings not an easy job.

In-depth investigations are also quite expensive. Given limited research budgets, there is a strong incentive to look for cheaper alternatives. Improving the efficiency and effectiveness of current research endeavours is possible in two areas: at the input level and at the inference level.

\section{Achieveable improvements at the input level}

A different type of study process is needed to reduce a possible negative impact of partial analysis at the case study level: synthesising. This enables a richer academic reasoning or inference regarding the subject of interest. Here the universe of discourse concerns the characteristics (i.e. the findings and the conditions) of a set of previously undertaken case studies. Using rules of inference, these study characteristics are placed into a relational structure [1].

\subsection{The approach in more detail}

For a single case study a scientist makes an a priori selection of the moderator variables. These variables and their complement, the not studied, yet existing remaining explanatory variables determine the universal set of moderator variables. Even if a vast number of case studies are undertaken these studies commonly do not fully overlap. According to [2], via synthetic study processes (e.g., narrative reviews and meta-analysis) differences among study outcomes can be related to differences in the study characteristics. So, when several case studies are simultaneously assessed a larger number of moderator variables and (cross-)interrelationships can be considered and new ones detected via network analysis [3]. Then, the joint complement of the collection of case studies under consideration reduces when another case study is added. Hence, the impact of the ceteris paribus clause is reduced. Figure 1 visualises the effect of variation among cases under study.

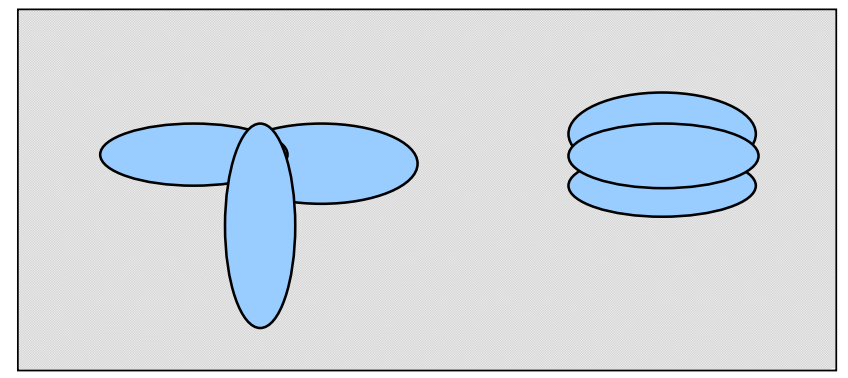

Figure 1: $\quad$ Small versus large variation (overlap).

If less variation means less coverage of the universal set of moderator variables, then it can be asked whether the limitation to a well-defined collection 
of case studies yields robust estimates and whether or not more, potentially redundant, studies should be included in the synthesis.

At first one might expect less variation to yield (more) robust estimates, but there is a heavier reliance on the ceteris paribus clause compared to the situation of more variation. A study into the optimal amount of overlap and variation among the collection of study findings would indeed be interesting.

In conclusion, synthetic study processes help to improve insight in how to find the optimal mix of studies that results in robust estimates.

\section{Quantifying the new insights}

The next step is to properly isolate and quantify these new moderator variables via network analysis. The most preferable technique is an automated type of inference that allows for their exploration and quantification. Stochastic inferences not only allow for the assessment of a large(r) set of case studies than the commonly used qualitative inferences, but this technique also allows handling the possible existence of incorrect and incomplete data. Furthermore, a stochastic inference allows a sound expansion of the universe of discourse. Via so-called data pooling the universe of discourse can be enlarged and a new estimate can be derived.

By increasing the number of case studies included in the synthesis a so-called convergence towards the truth is achieved [4], meaning a more robust estimate compared to the ones derived via case single studies. Besides the statistically sound pooling of various categories of data concerning environmental studies, it is worthwhile to consider the different types of case study more closely.

\subsection{Possible application areas}

In practice there are two main lines of environmental-economic valuation studies. First, there are case studies for 'pure' nature areas. There is no market for such public goods and the search is for robust aWTP- or CS-estimates in order to value (investments in) existing or planned nature areas. Non-market valuation techniques (e.g., CVM, HPM) are used to derive an aWTP-value. The result must be treated with care, because of the artificial market situation and strategic behaviour [5].

Second, there is social cost benefit analysis (CBA) for (smaller) areas that are not exclusive nature areas. CBA allows insights into the net benefit of investments in such facilities. Whereas non-market valuation techniques have a theoretical component, CBA can be considered as a purely empirical approach. Ideally, combining the insights and data derived via both approaches is preferable. First, because a larger universe of discourse is obtained, there are opportunities to derive more information from previously undertaken studies at a relatively low cost. Second, the combination allows empirical testing of the theoretical basis of non-market valuation techniques and analysis of the theoretical basis of CBA. Both may result in more realistic estimates. 
In the literature several (composite) valuation concepts can be found. In [6] a concept based on the land-use function of a site can be found. As any other (composite) valuation concept it aims to enclose all elements that add to the total economic value: the sum of the utility provided by the nature area under study. Practically, this approach combines the best of both worlds: within the Total Individual Value (TIV) the aWTP outcome is utilised and by the Total Functional Value (TFV) and Total Market Value (TMV) insights from CBAs are included in the inference, jointly adding up to the Total Economic Value (TEV) or

$$
T E V_{i}=\left(M_{i} \times a W T P_{i}\right)+T F V_{i}+T M V_{i}=T I V_{i}+T F V_{i}+T M V_{i} .
$$

where $M_{i}$ is the market area of site $i$. Care should be taken to avoid double counting. This involves a proper categorization of the three categories. Obviously, compared to regular studies this results in an endogenous value (the economic value of a site) that embraces a larger universe of discourse than one solely based on non-market valuation technique (the $T I V$ ) or CBA (the $T F V$ and/or $T M V$ ) case studies.

\subsubsection{The composite valuation concept explained}

From an economic perspective, ecosystems provide goods and services to society. Ecosystems consist of the following environmental components:

- physical media (soil, water, air, climate);

- biotic media (human beings, flora and fauna);

- perceptual media (landscape, scientific and cultural resources);

- and the interactions among the above-mentioned media.

Natural resources have a utility, a use value in economics. Ecologists go beyond that, and consider also other values unrelated to direct or indirect use. These non-use values arise from the psychological benefits derived from, among other things, the mere knowledge that the resource exists (existence value) or the wish to preserve natural capital for future generations to enjoy (inheritance value) [7]. The non-use values can be estimated via non-market valuation techniques.

The advantage of the composite valuation concept is that it provides a distinction between the non-use values (by the $T I V$ ) on the one hand, and the use values (via the $T F V$ and $T M V$ ) on the other. In this way a possible mixture of values generated by the market and those estimated in an artificial manner by non-market valuation techniques is avoided. This is relevant because of the possible drawbacks of the estimates derived by the latter resulting in less accurate estimates.

\subsubsection{Direct and indirect use values}

Direct use values (TMV) relate to the benefits from consumptive (an example is firewood) or non-consumptive use (such as tourism) of natural resources. Indirect use values relate to the indirect benefits from the primary ecological function of a given resource (such natural filtration of water). The latter type of values are also known as functional values (TFV). 
It can be concluded that the composite valuation as defined in (1) is compatible with the types of data presented in the literature. An advantage of (1) is that it clearly distinguishes between the non-use and use values, on the one hand, and the indirect and direct use values on the other at the same time. Such a distinction between direct and indirect use values can be arbitrary. However, their joint inclusion in (1) will eliminate such mistakes.

\section{The inference level: Searching for the best estimator}

A more careful consideration of the current research practice is necessary. For instance, regarding synthetical nature area valuation studies, narrative reviews as well as benefit transfer or meta-regression studies limit themselves to a so-called 'well-defined collection' of (almost identical) case studies that are undertaken earlier in time [8]. Hence, these inferences impose a limitation on the level of variety of the universe of discourse, resulting in a lower number of case studies that can be assessed, in the first place. This reduces the chances of initiating synthetic inferences and reduces the robustness of the estimates derived due to the smaller set of studies under consideration. Furthermore, as argued earlier, a variation among the case studies (in the sense of type, site characteristics studied, etc.) is preferable. Therefore, ex ante limitation to a set of almost identical case studies in the universe of discourse should be well thought off, also because it is likely to be unnecessary. However, this raises the question which inference (method / technique) fits (best) with this idea?

Classical statistics is commonly applied by scholars. For synthetical studies this is not different. A meta-regression may serve as an example. However, over time new studies of nature areas become available, and/or new sites are developed. From these studies new estimates of the value of certain site characteristics become available. How to use this information to bring science forward? As we will show, the best way to include these new study findings is not via classical statistics, but via Bayesian statistics, because this allows to thoroughly update previously derived estimates [9].

\subsection{Estimating the $T I V$}

The use of different estimators by different researchers may result in different study outcomes. It is interesting to analyse this issue further. For that purpose, we have collected 33 case studies of wetlands carried out over a longer period of time. We will estimate the aWTP-estimate via meta-regression and compare this with the same estimate derived via Bayesian statistics. To isolate the impact of the estimator on the study outcome, a data set is used that can be applied in both inferences. We limit the universe of discourse to the 'well-defined' collection of 33 studies. With this dataset, a valuation function is estimated by which the value of a planned nature area (wetland) with a size of $400 \mathrm{Ha}$ (=988.421 acres) [10] (also known as Het Kuindermeer) can be determined. The closest (middle-sized) city (Lelystad) is expected to generate the largest number of visits to this new nature area. 


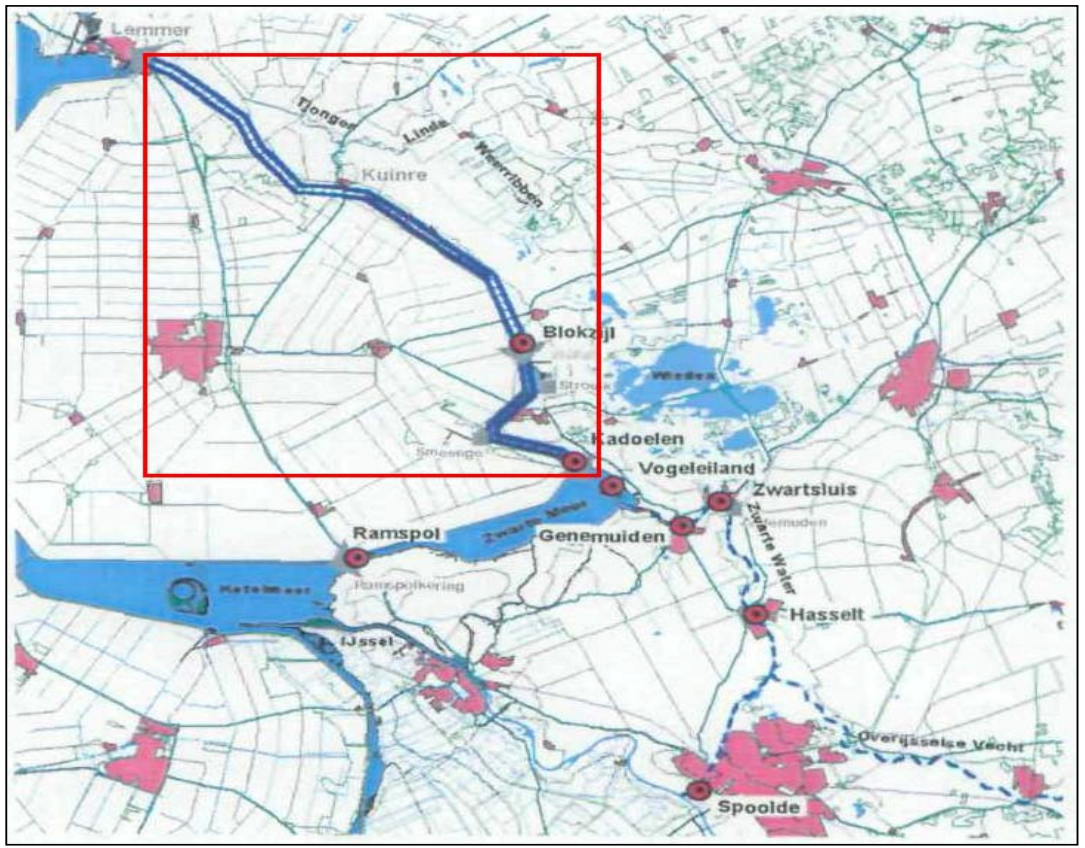

Figure 2: Location of Het Kuindermeer in the north-east of The Netherlands (province of flevoland).

\subsubsection{A classical meta-regression}

In case of a meta-regression the average income as well as the site size turn out to be predictors. With 30 degrees of freedom one finds that $R^{2}$ equals 0.3362 . The valuation function is as follows:

$$
a W T P_{K M}=-149,9123+0,0081 \text { alncome }_{K M}+0,0002 \text { Size }_{K M}
$$

If the average income of the privies of Het Kuindermeer is $€ 20.256$ per year [11], it follows that the $a W T P_{K M}$ is equal to 14,24 Euro per household per year.

A meta-regression enables to disclose and quantify variances in case studies. In order to obtain a reliable $a W T P$-estimate in a quantitative synthetic inference, the variances in and among the case studies need to be considered. Opposite to a meta-regression, a Bayesian inference allows for such considerations. This results in the following expression:

$$
a W T P_{K M}=-153,5222+0,0080 \text { alncome }_{K M}+0,0002 \text { Size }_{K M}
$$

Based on this valuation function it follows that the aWTP of Het Kuindermeer equals $€ 8,61$ per household per year. 


\subsubsection{A Bayesian estimation of the TIV}

Clearly, if there existed no within-study error, the aWTP-estimate out of a metaregression would have been equal to the one from the Bayesian approach. In this situation, this is not the case. Therefore, the application of a meta-analysis to estimate the aWTP for Het Kuindermeer must be rejected here. The Bayesian estimate can be considered as more accurate, in this respect.

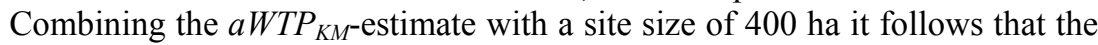
number of visitors for Het Kuindermeer $\left(M_{K M}\right)$ is approximately 385.464 per year [11]. The $a W T P$-estimate is for all households per year. With an average Dutch household size of 2.5 [12], the market area in terms of households is about 154.186. Given this market area estimate and the earlier derived $a W T P_{K M}$ one finds that the total of individual valuation is approximately equal to 1.326 .894 Euros yearly.

\subsection{A TFV-estimate}

Since the composite valuation concept of (1) is not used in previous research endeavours, the $T F V$ (and the $T M V$ alike) cannot be determined via a synthetic study process. However, the literature provides useable insights about (potential) functions of nature areas that support our endeavour sufficiently.

According to [13] the estimated net benefits of het Kuindermeer regarding water purification are around 38.800 Euros per year. Another function that this site could fulfil is flood protection. According to [11], the aggregated net benefit of increased flood protection by the existence of Het Kuindermeer is equal to 4.427.356 Euros per year. Furthermore, its presence increases the water buffering capacity in that area, preventing a reconstruction of dykes in response to an overall rising water level due to climate change and seasonal peaks in the river water level. According to [14] the increased water buffer capacity as a result of the presence of Het Kuindermeer will induce a one-time cost saving of at least 102.739.726 Euros. Over a 50-year time span (not uncommon for depreciation) this implies that the presence of the Kuindermeer generates a yearly benefit equal to 2.054.795 Euros. Adding the net value of water filtering and flood protection, one finds that the $T F V_{K M}$ is approximately 6.520 .950 Euros per year.

\subsection{A TMV-estimate}

An earlier cost-benefit study [15] estimated the net revenue from recreational activities and from the trade in natural resources. For recreation this figure is about (246.218.457*400/1600) 61.554.614 Euros whereas (by means of the value added per ha times the size of this economic activity in ha) the yearly net revenue from the exploitation of natural resources is about $(3782919 * 400 / 1600)$ 945.730 Euros. Hence, the $T M V_{K M}$ is approximately $(250.001 .376 * 400 / 1600)$ 62.500.344 Euros per year. 


\subsection{A TEV-estimate for het Kuindermeer}

Using the three elements of the composite valuation concept (1), the $T E V$ for this planned wetland can be derived. The $T E V_{K M}$ estimate is 70.348.188 Euros per year. According to [16] the net investment to establish Het Kuindermeer is equal to 475 million Euros. Hence, in light of the $T E V$-estimate it can be derived that funds invested in establishing Het Kuindermeer are regained within less than 7 years. In case only the $T M V$-value is considered: just slightly more than $71 / 2$ years. This makes it an interesting proposition from an economic perspective.

\section{New insights}

When comparing the composite valuation concept of equation (1) with the commonly used concepts, it is interesting to observe that the $T I V_{K M}$ adds just $1.9 \%$ to the $T E V$-estimate of Het Kuindermeer. Although our investigation is only concerned with the use-value of nature areas, the relatively low importance of the $T I V$ together with the high cost and limited reliability of the estimate, lead one to suggest that a shift in focus from the estimation of the $T I V$ to the estimation of the $T F V$ and $T M V$ seems to be the way forward in terms of research effectiveness and efficiency. Clearly, from a methodological point of view, more knowledge is enclosed in a synthetical study process compared to an analytical study endeavour. By adopting the composite valuation concept used in this paper an integral and largely bias-free quantitative assessment with a vast level of knowledge becomes available. This enables tackling several important anomalies in nature area valuation studies [17].

\section{Conclusions}

This paper showed that commonly used assumptions may unnecessarily limit nature area evaluation studies. Reducing the inferences to a well-defined collection of earlier undertaken case studies requires heavier reliance on the ceteris paribus clause. This implies less robust estimates. Combining outcomes from CVM studies with those from CBA studies leads to the interesting conclusion that the share of a $T I V$-estimate (derived via CVM) in the total economic value of a nature area is rather insignificant. This implies that cost benefit analysis is much more relevant than CVM methods when determining the use value of a site. If the robustness of estimates and the cost of in depth studies are taken into consideration, then quantitative synthetic study processes, in particular those using Bayesian statistics could be an interesting alternative to the commonly used approach based on classical statistics.

\section{References}

[1] Bal, F. and Nekkers, G.J.A., Knowledge Accumulation and Processing via Study Findings: Methodological Issues, Volkswirtschaftliche Diskussionsbeitrage No. 27, M. Luther Universität Halle-Wittenberg, Halle-Saale, 2001. 
[2] Bal, F. and Vleugel, J.M., Opening the Black Box of the Ceteris Paribus Clause, Volkswirtschaftliche Diskussionsbeitrage No. 46, M. Luther Universität Halle-Wittenberg, Halle-Saale, 2005.

[3] Capra, F., Web of Life: A New Synthesis of Mind and Matter, Flamingo, London, 1997.

[4] Glymour, C., Thinking Things Through, The MIT Press, Cambridge, 1992.

[5] Arrow, K.J., Learner, E., Portney, P., Radner, R., Schuman, H. and Solow, R., Report of NOAA Panel on Contingent Valuation, Federal Register 58(10), pp. 4601-4614, 1993.

[6] Bal, F. and Vleugel, J.M., On Composite Valuation Techniques for Manmade Natural Areas, Volkswirtschaftliche Diskussionsbeitrage No. 69, M. Luther Universität Halle-Wittenberg, Halle-Saale, 2011.

[7] ECLAC, Handbook for Estimating Socio-Economic and Environmental Effects of Disasters, Economic Commission for Latin America and the Caribbean (ECLAC), Mexico, 2009.

[8] EU DGXII, METAPOL: Final Report, Commission of the European Communities Environment Programme, Brussels, 1996.

[9] Berger, J.O., Statistical Decision Theory and Bayesian Analysis, 2nd edition, Springer-Verlag, Berlin, 1985.

[10] Van Empelen Van Aalderen Partners BV, Kuindermeer: Randmeer Noordoostpolder, Heemstede, 1998.

[11] Bos, E.J., Beschijving Randmeergebied 'Het Kuindermeer', Mimeo, Landbouw Economisch Instituut, Den Haag, 2000.

[12] Centraal Bureau voor de Statistiek, Regionale Economische Jaarcijfers 1997, Centraal Bureau voor de Statistiek, Voorburg /Heerlen, 1997.

[13] Mulder, M., Klaassen, M. and Vreke, J., Economische Graadmeters voor Natuur, DLO Natuurplanburo-onderzoek Werkdocument 1998/10, DLO, Den Haag, 1998.

[14] Dijkstra, A., Hendriks, E., Molen, P. van der, Posthoorn, P. and Rijsdorp, A., Schetsboek Randmeer Noordoostpolder, RIZA Werkdocument 2000.134, Rijksinstituut voor Integraal Zoetwaterbeheer en Afvalwaterbehandeling, Lelystad, 2000.

[15] Bos, E.J. and Bergh, J.C.J.M. van den, Economic Valuation, Land/Water Use and Sustainable Nature Conservation of 'De Vechtstreek' Wetlands, Tinbergen Institute Discussion Paper TI 98-036/3, Amsterdam, 1998.

[16] Van de Mei, H.T. and Rijsdorp, A.A. Randmeer langs de Noordoostpolder: Achtergrond-rapportage t.b.v. Integrale Visie IJsselmeergebied, RIZA Werkdocument 2000.008, Rijksinstituut voor Integraal Zoetwaterbeheer en Afvalwaterbehandeling, Lelystad, 2000.

[17] Vatn, A., Environmental Valuation and Rationality, Land Economics, 80(1), pp. 1-18, 2004. 